\title{
La tertulia en España: medios públicos, última frontera de la pluralidad
}

Recibido: 11/10/2010

Teodoro LEÓN GROSS

Universidad de Málaga

teo@uma.es

Bernardo J. GÓMEZ CALDERÓN

Universidad de Málaga

bjgomez@uma.es

Aceptado: 07/02/2011

\section{Resumen}

La tertulia política se ha consolidado como fórmula de referencia para la creación de opinión en los medios audiovisuales españoles, marcando la agenda y los enfoques de los temas proyectados a la opinión pública con un poderoso éxito de audiencia. Sin embargo, cabe dudar de su contribución efectiva al debate público toda vez que la pluralidad de opiniones que incorpora resulta, por lo general, muy escasa: las tertulias parecen regirse más por el sesgo ideológico que marcan sus respectivas cadenas que por una voluntad honesta de análisis de la actualidad política y social. Sólo los medios públicos escapan de esta disfunción, convirtiéndose en el último reducto de pluralidad del sistema audiovisual español

Palabras clave: Tertulia; géneros audiovisuales; pluralidad; medios públicos.

\section{The political talk show in Spain public media, the last frontier of the plurality}

\begin{abstract}
The political talk show has turned into a successful audio-visual genre in Spain. Nevertheless, it doesn 't contribute effectively to the public debate, due to its scant plurality of opinions. The political talk shows seem to be ruled by the ideological bias of the networks, instead of an honest will to analyze the political and social current affairs. Only the public media avoid this general handicap: they have become the last redoubt of plurality in the Spanish audio-visual media system.

Key words: Talk show; audio-visual genres; plurality; public media.

\section{Referencia normalizada}

LEÓN GROSS, Teodoro y GÓMEZ CALDERÓN, Bernardo J.(2011). "La tertulia en España: medios públicos, la última frontera de la pluralidad". Estudios sobre el mensaje periodístico. Vol. 17, núm. 1, págs. 67-80. Madrid, Servicio de Publicaciones de la Universidad Complutense.
\end{abstract}

Sumario: 1. Introducción. 2. Objetivos. 3. Metodología. 4. Resultados. 4. 1. Contertulios. 4. 2. Agenda. 4. 3. Actividad. 4. 4. Tono. 4. 5. Modalidad de discurso. 5. Conclusiones. 6. Referencias bibliográficas.

\section{Introducción}

Las tertulias, modalidad de género de alta vitalidad que ha superado cualquier resistencia de los medios de referencia hasta convertirse en una solución imprescindible en la creación de opinión en el entorno audiovisual, constituyen un espejo interesante para evaluar algunos valores imperantes en el ideario periodístico. Su éxito está fuera de duda y de hecho se reproducen en la práctica totalidad de los medios, siguiendo siempre pautas similares, lo cual obedece a la ya característica homogeneidad del sistema audiovisual español, compuesto por emisores que afrontan la competencia directa sin apenas actuaciones alternativas y entre los que "el miedo a la innovación está extendido" (GuTIÉRREZ y HuERTAS, 2003: 134), aunque ello también responde a un fenómeno estructural de mayor recorrido, la concentración (cf. COLLINS y MORONI, 1996). 
El formato y la dinámica de la tertulia como género periodístico audiovisual se encuentran perfectamente asentados. Su identidad emana de la figura del conductor, convertido en icono de la propia cadena, que tanto al moderar como al explicitar su punto de vista define el temario, pero también el tono, el perfil dramático y el encuadre desde el que se abordan los temas. Los contertulios siguen esas pautas, y en su discurso combinan información, interpretación y opinión, con predominio de esta última. En cuanto a la agenda, aparece monopolizada por la actualidad perentoria, abordada sin exhaustividad deliberativa: nos encontramos ante un género de carácter dialógico más informal que el debate, menos riguroso en su estructura y en la exposición de los temas, y en el que se pasa de unos asuntos a otros sin necesidad de haber alcanzado conclusiones previas.

$\mathrm{Su}$ naturaleza espontánea conlleva que en la tertulia haya, más que enfrentamiento dialéctico, simple acumulación o yuxtaposición de opiniones. A menudo prevalece el ingenio sobre la argumentación sólida y estructurada, y no es frecuente una defensa acérrima de las posturas, que se expresan más bien en un lenguaje coloquial (MARTínez-Costa PÉReZ y DAMAs, 2008).

A pesar de la hibridación de elementos que con frecuencia presenta, cabe considerar la tertulia una modalidad coral de género opinativo, en el que los contenidos informativos, interpretativos y explicativos cumplen siempre la función de apuntalar los juicios de los participantes, con mayor o menor fortuna. $Y$ de acuerdo con su adscripción argumentativa, no ha de extrañar que la teoría de los géneros periodísticos renuncie a asignarle pautas estrictas de codificación (cf. CEBRIÁN Herreros, 1992; SÁnCHEZ SERRANO, 1994 y 2006; ArmañanZAS y DíAZ Noci, 1997; SANTAMARÍA Y CASALS CARRO, 2000; entre otros), puesto que casi todo vale en la tertulia, y ni siquiera los libros de estilo de las cadenas de radio y televisión, por lo demás escasos, aciertan a ofrecer de ella más que vagas prescripciones ${ }^{1}$.

Los datos de audiencia en la franja matinal evidencian que se trata de un formato de amplia aceptación, especialmente en el caso de las cadenas de radio, como ponen de manifiesto las sucesivas oleadas del Estudio General de Medios. Así, los emisores generalistas cosechan las cifras de seguimiento más abultadas durante el espacio ocupado por las tertulias de mañana: SER, con "Hoy por Hoy", 2,660.000 oyentes; Onda Cero, con "Herrera en la Onda", 1.820.000; Radio Nacional de España, con "En días como hoy", 1.262.000; Cope, con "La Mañana", 897.000; y Punto Radio, con "Protagonistas", $345.000^{2}$.

${ }^{1}$ Hasta la fecha y en el terreno audiovisual, sólo se han comercializado en España los libros de estilo de Telemadrid (1993), Onda Cero (1996) y Canal Sur Televisión (2004). La cadena Cope anunció en 2003 una guía de estilo para uso exclusivo de sus redactores, y en fecha reciente (junio de 2010), RTVE ha aprobado un manual de naturaleza similar cuyo contenido no ha trascendido. De los disponibles, sólo el libro de estilo de Onda Cero se ocupa de la tertulia, destacando su propósito analítico y la obligación de los invitados de conocer "en profundidad" los asuntos que se tratan en ella (1996: 29-31).

${ }^{2}$ Los datos proceden de la oleada del Estudio General de Medios correspondiente al intervalo abril-mayo de 2010. 
Además, el éxito de la tertulia se proyecta en la parrilla de las cadenas a lo largo de toda la jornada, de lunes a domingo, de modo que, además de las emisiones matinales abordadas en este trabajo, hay tertulias antes de los informativos del mediodía, tertulias de tarde con un perfil arrevistado como sucede durante el fin de semana, y tertulias de carácter más reflexivo en horario nocturno.

\section{Objetivos}

Denostadas en ocasiones aunque, como sugiere NúÑEz LADEVÉzE (1995: 117), más por motivos ideológicos o políticos que estrictamente periodísticos, las tertulias matinales actúan como soporte de jerarquización de la agenda al fijar el temario dominante y sus encuadres. Pero la percepción de que antenizan el mapa ideológico del país, atomizando la pluralidad y renunciando por consiguiente a actuar como catalizadores de la propia opinión pública, pone en cuestión su verdadero valor. Ese carácter cerrado puede parecer un comportamiento singular, toda vez que en la actualidad forman parte de una cultura mediática más abierta y dinámica alentada por Internet, donde los ciudadanos proyectan su diversidad con "caminos prometedores y resultados palpables” para la colaboración social (GARCíA DE MADARIAGA, 2006: 210).

Esto anima a cuestionarse sobre la contribución de las tertulias a la pluralidad -entendiendo que el pluralismo se mantiene como horizonte consustancial a la cultura mediática de referencia (Murciano, 2006), pese a resultar "un valor difícil de promover" (Miguel DE Bustos, 2004: 25)-, y a indagar sobre el perfil real de unos espacios que tanta influencia ejercen sobre la agenda pública de debate (SÁnCHEZ SERRANO, 2006).

Este trabajo se propone determinar si la diversidad de ideas está presente en las tertulias o si, por el contrario, se ha renunciado a ella, convirtiendo el género en un espectáculo definido por el sesgo ideológico, reflejo del atrincheramiento partidista, con la consiguiente lesión de la calidad de la cultura mediática -y, por extensión, democrática- del país. Se trata de objetivar la pluralidad de opiniones existente o la identificación coral con la línea editorial de las respectivas cadenas, atendiendo a las posturas de los participantes, los temas sobre los que se pronuncian, el tono adoptado en la exposición y el carácter crítico o complaciente de su discurso. Asimismo, se pretenden establecer eventuales diferencias formales y de estructura entre las tertulias radiofónicas y las televisivas.

\section{Metodología}

El corpus de la investigación lo componen las tertulias matinales de los medios audiovisuales españoles de mayor seguimiento, esto es, las cinco emisoras de radio generalistas de implantación nacional y las cuatro cadenas de televisión de idéntica cobertura:

- SER. Espacio: “El abierto de Hoy por hoy”. Conductor: Carles Francino.

- Onda Cero. Tertulia integrada en el espacio "Herrera en la onda”. Conductor: Carlos Herrera.

- Cope. Tertulia integrada en el espacio "La mañana”. Conductor: Ignacio Villa. 
- Radio Nacional de España. Tertulia integrada en el espacio "En días como hoy”. Conductor: Juan Ramón Lucas.

- Punto Radio. Tertulia integrada en el espacio “Protagonistas”. Conductor: Félix Madero.

- TVE. Tertulia integrada en el espacio "Los desayunos de TVE”. Conductora: Ana Pastor.

- Antena 3. Espacio: “El ring”. Conductora: Susana Grisso.

- Telecinco. Espacio: "La tertulia de Ana Rosa”. Conductora: Ana Rosa Quintana.

- Cuatro. Tertulia integrada en el espacio "Matinal Cuatro". Conductora: Ana García Siñeriz ${ }^{3}$.

Para ofrecer una perspectiva autonómica complementaria, se han analizado también las tertulias matinales de Canal Sur Radio ("La hora de Andalucía”, dirigida por Tom Martín Benítez) y Canal Sur Televisión (“El meridiano”, moderada por Mabel Mata). El periodo de estudio abarca del 19 al 23 de abril de 2010, lo que equivale a un total de 55 emisiones.

El análisis de contenido se antoja una solución competente para investigaciones de este tipo, toda vez que, como ya apuntaba KRIPPENDORFF (2002: 28), persigue "hacer inferencias reproducibles y válidas de los datos al contexto de los mismos", o en palabras de Laurence BARDIN (1996: 32), "explotar indicadores válidos y objetivos para inferir un conocimiento acerca de las condiciones de producción/recepción”. Su condición de herramienta óptima para recopilar, procesar y evaluar grandes cantidades de información (SÁNCHEZ ARANDA, 2005: 214), así como su utilización frecuente en la descripción de los componentes de los mensajes mediáticos (IgARTUA, 2006: 194), la convierten en el método de indagación más apropiado para nuestro trabajo.

Así, a cada emisión seleccionada se le ha aplicado una ficha de análisis compuesta por categorías tanto formales como de contenido:

a) Contertulios: número, sexo, nombre, perfil profesional y actitud pro o antigubernamental.

b) Agenda: repertorio de temas, sección a la que se adscriben, dimensión -local, regional, nacional o internacional-y tiempo de tertulia dedicado a cada uno de ellos.

c) Actividad: muy crítica, crítica, neutral, complaciente o muy complaciente con el Gobierno central o autonómico.

d) Tono: moderado, humorístico, dramático, irónico o deliberativo.

e) Modalidad de discurso: informativo, interpretativo o doctrinal ${ }^{4}$.

${ }^{3}$ La Sexta no dispone de tertulia en esa franja horaria.

${ }^{4}$ Han colaborado en el análisis los siguientes doctorandos del programa "Periodismo: Nuevos escenarios” (Universidad de Málaga, curso 2009/2010): Marta Castillo, Francisco Javier Cristófol, Ascensión Cubillo, Ruth de Frutos, Angelo di Placido, Mercedes Díaz, Francisco García, Juan Tomás Luengo Estíbaliz Martínez, Lorena Parra, Lydia Rosado, Roberto Ruiz, Anabel Seisdedos, Estefanía Vera y Guillermo Villalobos. 


\section{Resultados}

\section{1. Contertulios}

La elección de los contertulios evidencia una línea editorial bien definida en la mayor parte de los casos, reduciendo -cuando no haciendo desaparecer por completo- la pluralidad de opiniones. Son minoría las cadenas que tratan de presentar un abanico de posturas amplio: el caso más destacado es el de Radio Nacional de España, en cuya tertulia, conducida por Juan Ramón Lucas, se reparten equitativamente las voces a favor y en contra del Gobierno central (53,3 frente a 46,7 por ciento). En el otro extremo se sitúan SER y Cope: ambas presentan más de un 90 por ciento de contertulios alineados en el mismo bando, favorable al Ejecutivo en el primer caso y opuesto a él, a veces con virulencia, en el segundo.

Hay un tercer grupo de tertulias radiofónicas que, pese a mantener una orientación editorial clara, cuentan en cada emisión con participantes alejados de la postura mayoritaria. Así ocurre en Onda Cero Radio, Punto Radio -ambas escoradas al centro-derecha- y Canal Sur Radio -favorable al Gobierno de la Junta-.

Cabe reseñar que, cuando los contertulios proceden de esferas profesionales distintas del periodismo, opción a la que recurren Onda Cero, Cope, Punto Radio y Canal Sur, la postura mayoritaria suele ser crítica con el Ejecutivo ${ }^{5}$.

Tabla 1. Actitud de los participantes en tertulias radiofónicas

\begin{tabular}{|l|r|r|r|r|r|r|r|}
\hline \multicolumn{1}{|c|}{ Actitudes } & \multicolumn{7}{|c|}{ Emisoras } \\
\hline & $\begin{array}{c}\text { SER } \\
(\%)\end{array}$ & $\begin{array}{c}\text { OCR } \\
(\%)\end{array}$ & $\begin{array}{c}\text { COPE } \\
(\%)\end{array}$ & $\begin{array}{c}\text { RNE } \\
(\%)\end{array}$ & $\begin{array}{c}\text { PR } \\
(\%)\end{array}$ & $\begin{array}{c}\text { CSR } \\
(\%)\end{array}$ & $\begin{array}{c}\text { Total } \\
(\%)\end{array}$ \\
\hline Actitud progubernamental & 90,5 & 15,0 & 6,7 & 53,3 & 13,0 & 50,0 & 38,6 \\
\hline Actitud antigubernamental & 9,5 & 75,0 & 86,7 & 46,7 & 82,6 & 10,0 & 50,9 \\
\hline $\begin{array}{l}\text { Políticos o profesionales } \\
\text { progubernamentales }\end{array}$ & 0,0 & 0,0 & 0,0 & 0,0 & 0,0 & 20,0 & 3,5 \\
\hline $\begin{array}{l}\text { Políticos o profesionales } \\
\text { antigubernamentales }\end{array}$ & 0,0 & 10,0 & 6,7 & 0,0 & 4,3 & 20,0 & 7,0 \\
\hline \multicolumn{1}{|c|}{ Total } & 100,0 & 100,0 & 100,0 & 100,0 & 100,0 & 100,0 & 100,0 \\
\hline
\end{tabular}

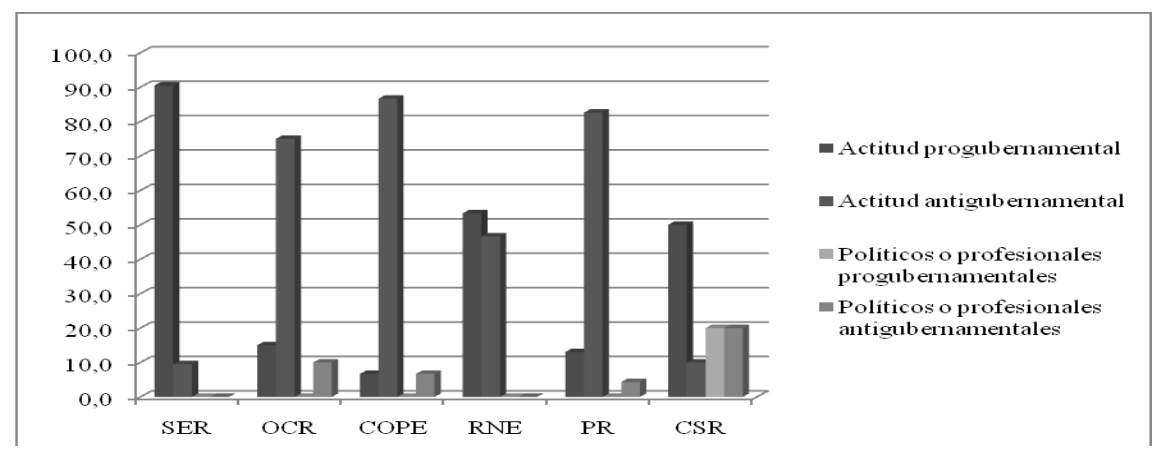

Figura 1. Actitud de los participantes en tertulias radiofónicas.

${ }^{5}$ La muestra ha permitido analizar las aportaciones de 114 contertulios radiofónicos, distribuidos del siguiente modo: SER: 21; Onda Cero: 20; Cope: 15; RNE: 15; Punto Radio: 23; Canal Sur Radio: 20. 
En cuanto a las cadenas de televisión, los porcentajes se presentan algo más equilibrados. De nuevo es el emisor público nacional, TVE, el que acoge a un elenco de contertulios de adscripción ideológica más variada (53,4 por ciento favorable al Gobierno, 36,6 desfavorable), y otro tanto cabe reseñar a propósito de Canal Sur Televisión, en cuya tertulia matinal los periodistas, políticos o profesionales invitados que mantienen posturas críticas con el gobierno autonómico alcanzan el 45 por ciento.

Telecinco y Cuatro, aun mostrando una orientación general clara -opuesta y favorable a las políticas de Rodríguez Zapatero, respectivamente-, parecen preocuparse más por la pluralidad de voces, y en ambas la tasa de participantes que no coinciden con la línea editorial de la cadena roza el 33 por ciento.

La única tertulia en exceso monocorde es la que conduce Susana Grisso en Antena 3: en ella, el índice de comentaristas críticos con el Gobierno alcanza el 86,7 por ciento.

Del mismo modo que en la radio, cuando en televisión se incluye entre los contertulios a políticos o profesionales de otros ámbitos (algo habitual salvo en la tertulia de Cuatro), estos suelen exhibir posturas antigubernamentales ${ }^{6}$.

Tabla 2. Actitud de los participantes en tertulias televisivas

\begin{tabular}{|l|r|r|r|r|r|r|}
\hline \multicolumn{1}{|c|}{ Actitudes } & \multicolumn{6}{c|}{ Cadenas } \\
\hline & $\begin{array}{c}\text { TVE } \\
(\%)\end{array}$ & $\begin{array}{c}\text { A3 } \\
(\%)\end{array}$ & $\begin{array}{c}\text { CUATRO } \\
(\%)\end{array}$ & $\begin{array}{c}\text { T5 } \\
(\%)\end{array}$ & $\begin{array}{l}\text { CSTV } \\
(\%)\end{array}$ & \multicolumn{1}{c|}{$\begin{array}{c}\text { Total } \\
(\%)\end{array}$} \\
\hline Actitud progubernamental & 46,7 & 13,3 & 66,7 & 30,0 & 40,0 & 40,0 \\
\hline Actitud antigubernamental & 33,3 & 80,0 & 33,3 & 60,0 & 15,0 & 40,0 \\
\hline $\begin{array}{l}\text { Políticos o profesionales } \\
\text { progubernamentales }\end{array}$ & 6,7 & 0,0 & 0,0 & 0,0 & 15,0 & 5,3 \\
\hline $\begin{array}{l}\text { Políticos o profesionales } \\
\text { antigubernamentales }\end{array}$ & 13,3 & 6,7 & 0,0 & 10,0 & 30,0 & 12,0 \\
\hline \multicolumn{1}{|c|}{ Total } & 100,0 & 100,0 & 100,0 & 100,0 & 100,0 & 100,0 \\
\hline
\end{tabular}

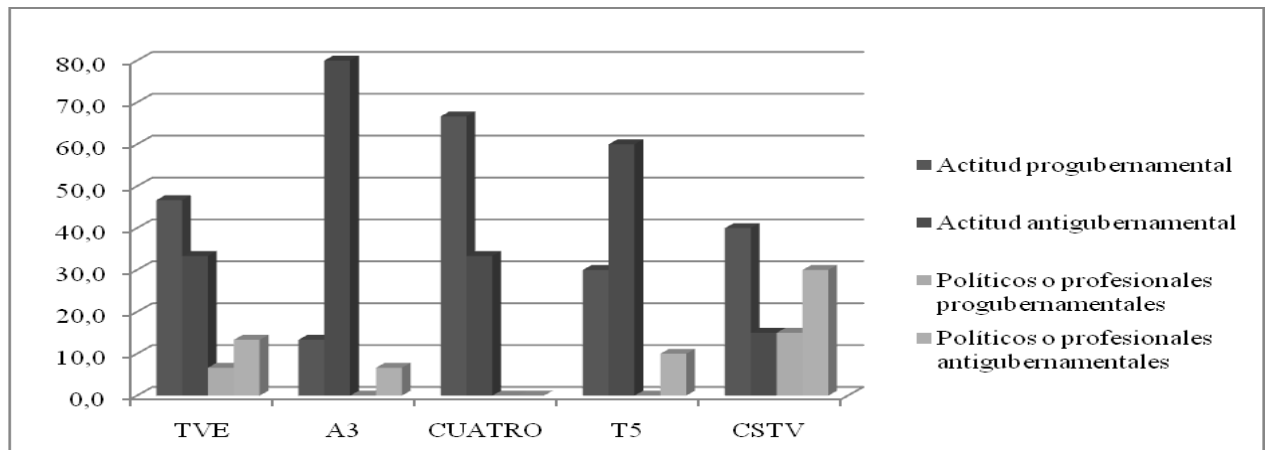

Figura 2. Actitud de los participantes en tertulias televisivas

Hay tertulias que podemos denominar endogámicas, pues recurren de forma habitual a profesionales de la casa, como las de SER o Punto Radio; y otras, las más,

${ }^{6}$ Los contertulios televisivos de todas las cadenas suman 75, distribuidos así: TVE: 15; Canal Sur Televisión: 20; Antena 3: 15; Cuatro: 15; Telecinco: 10. 
que cuentan sólo con periodistas y opinadores cuya actividad se desarrolla en el ámbito de los medios impresos, como directores de diarios nacionales y columnistas de renombre (esto último es lo más frecuente en las tertulias televisivas). En este sentido, sigue vigente la dinámica observada en su momento por CEBRIÁn HeRreros, según el cual la tertulia "no crea figuras populares sino que se aprovecha de las que ya lo son" (1992: 448); por ello, en muchos casos, estos espacios funcionan como caja de resonancia de opiniones ya expresadas a través de la prensa escrita.

En cuanto al papel de los conductores de las tertulias, los hay neutrales y los hay que opinan, azuzan el debate e incluso adoctrinan. Entre los primeros, destacan los adscritos a medios de titularidad pública, como Juan Ramón Lucas (RNE), Ana Pastor (TVE) y Mabel Mata (Canal Sur Televisión), así como a cadenas de televisión nacionales: Susana Grisso (Antena 3), Ana Rosa Quintana (Antena 3) y Ana García Siñeriz (Cuatro). Directores menos neutrales resultan Carlos Herrera (Onda Cero), Félix Madero (Punto Radio) y Carles Francino (SER), mientras que Tom Martín Benítez (Canal Sur Radio) e Ignacio Villa (Cope) no tienen reparo en opinar abierta y continuadamente. La casuística, por tanto, es variada.

En general, los moderadores de tertulias televisivas se muestran más cautos a la hora de intervenir en los debates que los de radio.

Por otro lado, una tendencia acusada de las tertulias políticas, tanto radiofónicas como televisivas, es el predominio de participantes masculinos. Hay disparidad en los índices, pero las mujeres nunca sobrepasan el 30 por ciento del total de contertulios: en la cadena SER, la más igualitaria, constituyen el 28,6 por ciento. A partir de ahí, los porcentajes oscilan entre el 20 por ciento de Onda Cero y Canal Sur Radio, y el exiguo 6,7 de Radio Nacional de España. El saldo global es un apabullante 80,5 por ciento de hombres, a lo que hay que sumar, además, la condición masculina de todos los conductores.

Tabla 3. Distribución por sexos de los contertulios radiofónicos

\begin{tabular}{|l|r|r|r|r|r|r|r|}
\hline & \multicolumn{1}{|c|}{$\begin{array}{c}\text { SER } \\
(\%)\end{array}$} & $\begin{array}{c}\text { OCR } \\
(\%)\end{array}$ & $\begin{array}{c}\text { COPE } \\
(\%)\end{array}$ & $\begin{array}{c}\text { RNE } \\
(\%)\end{array}$ & \multicolumn{1}{c|}{$\begin{array}{c}\text { PR } \\
(\%)\end{array}$} & \multicolumn{1}{c|}{$\begin{array}{c}\text { CSR } \\
(\%)\end{array}$} & \multicolumn{1}{c|}{$\begin{array}{c}\text { Total } \\
(\%)\end{array}$} \\
\hline Hombres & 71,4 & 80,0 & 86,7 & 93,3 & 82,6 & 80,0 & 80,5 \\
\hline Mujeres & 28,6 & 20,0 & 13,3 & 6,7 & 17,4 & 20,0 & 19,5 \\
\hline Total & 100,0 & 100,0 & 100,0 & 100,0 & 100,0 & 100,0 & 100,0 \\
\hline
\end{tabular}

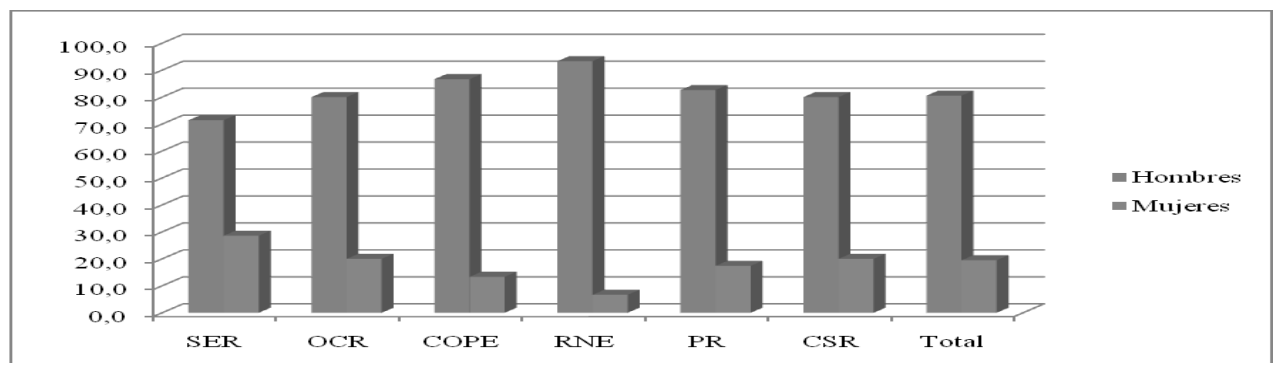

Figura 3. Distribución por sexos de los contertulios radiofónicos 
Las tertulias televisivas presentan porcentajes más equilibrados, siendo TVE la cadena con menor brecha entre géneros, pues acoge a un 40 por ciento de mujeres. En tasas similares se sitúan Canal Sur Televisión y Cuatro, y sólo la tertulia de Ana Rosa Quintana en Telecinco exhibe una abrumadora mayoría masculina (90 por ciento de participantes). Merece reseñarse que, en franca oposición a lo que ocurre en el medio radiofónico, todos los espacios televisivos analizados están moderados por mujeres, lo cual contribuye a equiparar los índices.

Tabla 4. Distribución por sexos de los contertulios televisivos

\begin{tabular}{|l|r|r|r|r|r|r|}
\hline & \multicolumn{1}{|c|}{$\begin{array}{c}\text { TVE } \\
(\%)\end{array}$} & \multicolumn{1}{c|}{$\begin{array}{c}\text { A3 } \\
(\%)\end{array}$} & $\begin{array}{c}\text { CUATRO } \\
(\%)\end{array}$ & \multicolumn{1}{c|}{$\begin{array}{c}\text { T5 } \\
(\%)\end{array}$} & \multicolumn{1}{c|}{$\begin{array}{c}\text { CSTV } \\
(\%)\end{array}$} & \multicolumn{1}{c|}{$\begin{array}{c}\text { Total } \\
(\%)\end{array}$} \\
\hline Hombres & 60,0 & 73,3 & 66,7 & 90,0 & 65,0 & 69,3 \\
\hline Mujeres & 40,0 & 26,7 & 33,3 & 10,0 & 35,0 & 30,7 \\
\hline Total & 100,0 & 100,0 & 100,0 & 100,0 & 100,0 & 100,0 \\
\hline
\end{tabular}

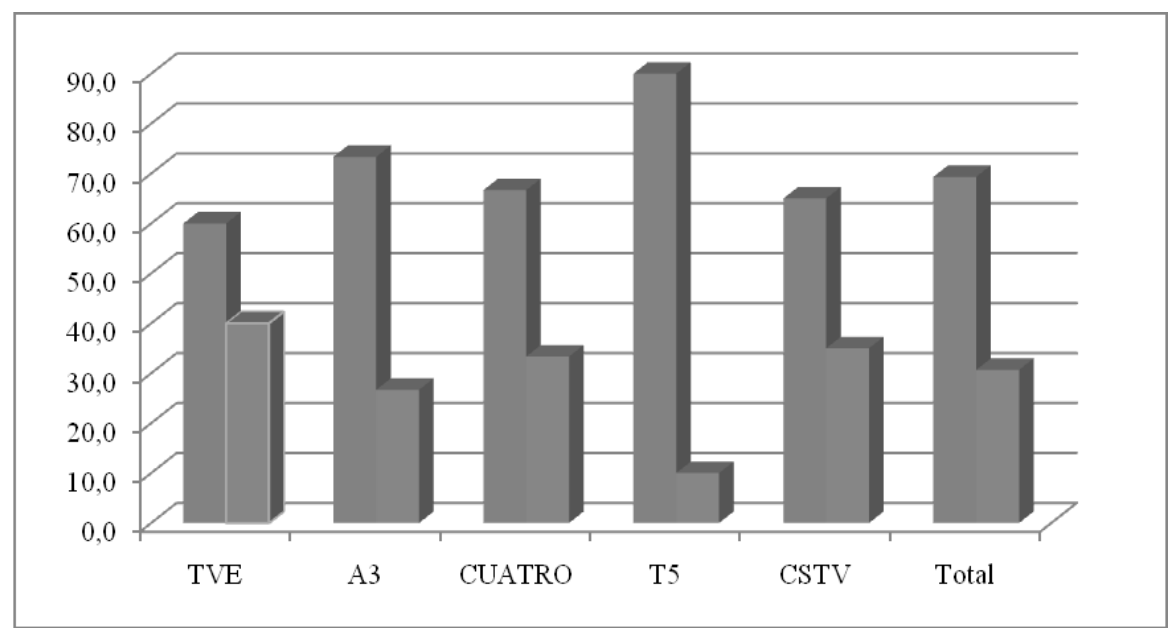

Figura 4. Distribución por sexos de los contertulios televisivos

\section{2. Agenda}

La política nacional constituye casi en exclusiva el foco de atención de las tertulias de radio y televisión, aunque con matices, ya que estas últimas se deslizan a veces, sobre todo en el tramo final de sus emisiones, hacia cuestiones más frívolas. La actualidad internacional sólo atrae la atención de los contertulios cuando tiene implicaciones nacionales directas.

La actualidad de la semana sometida a análisis viene marcada por varios asuntos: la renuncia del tesorero del PP Luis Bárcenas a su escaño de senador; la polémica en torno al uso del velo islámico, después de que un colegio de Pozuelo de Alarcón decidiera mantener la prohibición del hiyab en sus aulas; el caos aéreo derivado de la erupción del volcán islandés Eyjafjallajokull -un tema internacional al que se aplica enfoque doméstico-, la imposibilidad del Tribunal Constitucional para emitir una sentencia sobre el recurso presentado por el PP contra el Estatut de Cataluña, y 
la reforma del sistema educativo planteada por el Gobierno. El primero y el cuarto, temas de neta adscripción política, se prestan a adoptar posicionamientos claros, que sirven para determinar el sesgo de los contertulios.

El hecho de que alguno de estos asuntos no se incluya en la agenda de una cadena o emisora dice mucho de la orientación de la misma, pues no hay que perder de vista que "la elección de temas supone una toma de postura inicial por parte de la dirección de la tertulia” (SÁnchEz, 2006: 147). Así, ni Cope ni Onda Cero se ocupan en toda la semana del caso Bárcenas, y Punto Radio sólo lo hace en una ocasión, mientras que la cobertura que le dispensan SER y Cuatro es mucho más generosa.

En función de la línea editorial, se presta atención a cuestiones de menor relevancia como la causa abierta por el Supremo contra Baltasar Garzón por supuesta prevaricación (Cope la aprovecha para arremeter contra el juez durante toda la semana, Cuatro para defenderlo hasta en tres ocasiones) o la retirada a Viajes Marsans, empresa propiedad del presidente de la CEOE, Gerardo Díaz Ferrán, de la licencia para vender pasajes de avión (RNE y Cuatro llaman reiteradamente la atención sobre este hecho, mientras que el resto de las cadenas obvia la noticia).

Sólo de forma marginal se aborda la crisis económica, en TVE atendiendo sobre todo a sus implicaciones internacionales, y desde una óptica nacional -y en tono, a ratos, dramático- en Cope, Punto Radio y Antena 3.

En cuanto a Canal Sur, mantiene una agenda marcada por la actualidad política nacional, lo cual parece contravenir su condición de ente público autonómico, y los temas regionales a los que atiende suelen carecer de aristas políticas. Así, durante la semana analizada se abordan cuestiones como las candidaturas de Málaga y Córdoba a la capitalidad cultural europea en 2016, el arranque de la Feria de Sevilla o el Festival de Cine Español de Málaga. Sólo una vez se menciona el caso Mercasevilla, que compromete al equipo de gobierno del Ayuntamiento de la capital, en Canal Sur Radio, y se hace un escueto y acrítico balance del primer año de gestión de José Antonio Griñán al frente de la Junta, en la tertulia de Mabel Mata. No estamos, parece obvio, ante una contribución relevante al debate político regional.

\section{3. Actividad}

Hay un predominio claro de la actividad crítica en el marco de las tertulias analizadas. Es el modo habitual de conducirse en los casos de Onda Cero y Punto Radio, y en cuanto a Cope, lo más frecuente es que su actividad alcance la categoría de muy crítica. Frente a ello, algunas cadenas (Ser, Canal Sur Radio) mantienen una actitud complaciente con el Gobierno. La tasa de neutralidad varía en función de los emisores, pero como norma general es reducida, salvo en la tertulia que dirige Juan Ramón Lucas en Radio Nacional de España.

Tabla 5. Actividad de los contertulios radiofónicos

\begin{tabular}{|l|c|c|c|c|c|c|}
\hline & $\begin{array}{c}\text { SER } \\
(\%)\end{array}$ & $\begin{array}{c}\text { OCR } \\
(\%)\end{array}$ & $\begin{array}{c}\text { COPE } \\
(\%)\end{array}$ & $\begin{array}{c}\text { RNE } \\
(\%)\end{array}$ & $\begin{array}{c}\text { PR } \\
(\%)\end{array}$ & $\begin{array}{c}\text { CSR } \\
(\%)\end{array}$ \\
\hline Muy crítica & & & 80 & & & \\
\hline Crítica & & 80 & 20 & & 80 & \\
\hline Neutral & 20 & 20 & & 100 & 20 & 20 \\
\hline Complaciente & 80 & & & & & 80 \\
\hline Muy complaciente & & & & & & \\
\hline
\end{tabular}




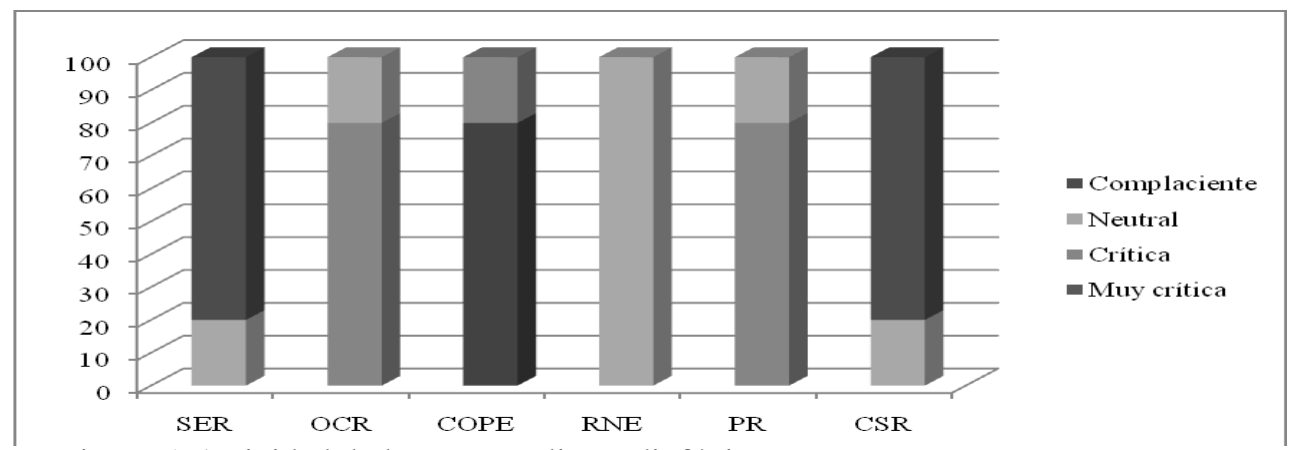

Figura 5. Actividad de los contertulios radiofónicos.

Algo más neutrales resultan las tertulias televisivas, en especial las de TVE, Canal Sur Televisión y Cuatro; estas dos últimas, sin embargo, se deslizan con frecuencia hacia planteamientos abiertamente favorables a las posiciones del Gobierno central o autonómico, restando mordiente a sus planteamientos. En Telecinco, son más habituales las críticas al Ejecutivo que los elogios, mientras que en la tertulia que conduce Susana Grisso en Antena 3, todas las opiniones son en mayor o menor medida antigubernamentales.

Tabla 6. Actividad de los contertulios televisivos

\begin{tabular}{|l|c|c|c|c|c|}
\hline & $\begin{array}{c}\text { TVE } \\
(\%)\end{array}$ & $\begin{array}{c}\text { A3 } \\
(\%)\end{array}$ & $\begin{array}{c}\text { CUATRO } \\
(\%)\end{array}$ & $\begin{array}{c}\text { T5 } \\
(\%)\end{array}$ & $\begin{array}{c}\text { CSTV } \\
(\%)\end{array}$ \\
\hline Muy crítica & & 40 & & & \\
\hline Crítica & & 60 & & 80 & \\
\hline Neutral & 100 & & 60 & 20 & 60 \\
\hline Complaciente & & & 40 & & 40 \\
\hline Muy complaciente & & & & & \\
\hline
\end{tabular}

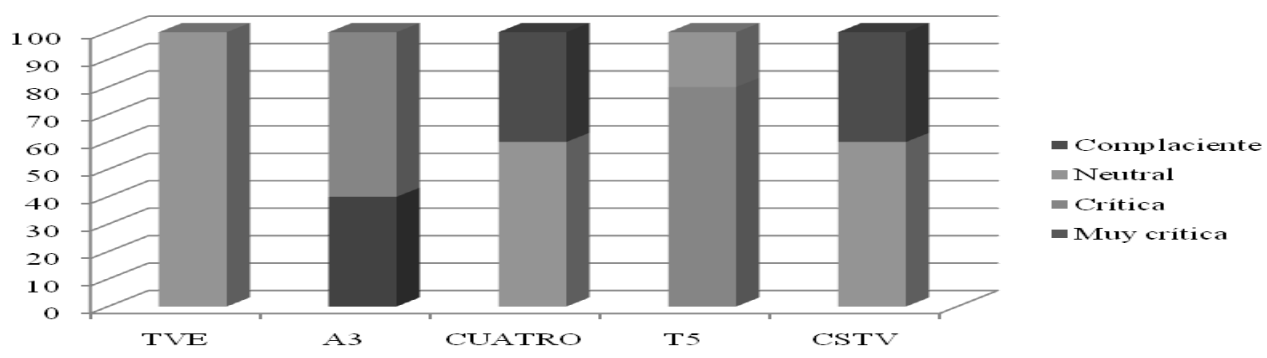

Figura 6. Actividad de los contertulios televisivos

\section{4. Tono}

Al margen de la línea editorial de cada medio, lo cierto es que el tono del debate suele ser moderado en la mayor parte de las tertulias radiofónicas analizadas. Sólo de forma esporádica se adopta un enfoque humorístico (Canal Sur Radio) o irónico 
(Punto Radio y Onda Cero, en ambos casos cuando se abordan las iniciativas más polémicas del Gobierno).

La excepción en este terreno la constituye, de nuevo, Cope, en la que abunda el discurso deliberativo (60\% de las intervenciones) y se recurre a veces a una exposición abiertamente dramática que apela sin rubor al pathos de los oyentes.

Tabla 7. Tono de los contertulios radiofónicos

\begin{tabular}{|l|c|c|c|c|c|c|}
\hline & $\begin{array}{c}\text { SER } \\
(\%)\end{array}$ & $\begin{array}{c}\text { OCR } \\
(\%)\end{array}$ & $\begin{array}{c}\text { COPE } \\
(\%)\end{array}$ & $\begin{array}{c}\text { RNE } \\
(\%)\end{array}$ & $\begin{array}{c}\text { PR } \\
(\%)\end{array}$ & $\begin{array}{c}\text { CSR } \\
(\%)\end{array}$ \\
\hline Moderado & 100 & 60 & & 100 & 80 & 40 \\
\hline Humorístico & & & 20 & & & 60 \\
\hline Dramático & & & 20 & & & \\
\hline Irónico & & 40 & & & 20 & \\
\hline Deliberativo & & & 60 & & & \\
\hline
\end{tabular}

En el caso de las tertulias televisivas, todas hacen gala de un tono moderado que no deja sitio para las diatribas exaltadas que a veces se deslizan en radio. Las posturas se defienden con menor virulencia, los conductores exhiben un ánimo más contemporizador y hay espacio para ocasionales salidas humorísticas al abordar temas de índole cultural o social (soft news), hacia el final de las emisiones.

\section{5. Modalidad de discurso}

Finalmente, en cuanto a las modalidades de discurso, hay un predominio claro de la interpretación en la exposición de los contertulios, con más peso de los contenidos informativos en "Los desayunos de TVE" que conduce Ana Pastor y en las tertulias de Cuatro y Canal Sur. Algunas cadenas de radio, no obstante, emplean un discurso doctrinal, caso de Punto Radio (20 por ciento de los casos) y, sobre todo, Cope (80 por ciento).

Se aprecian, en este sentido, diferencias notables entre las tertulias televisivas y las radiofónicas, pues aquellas conceden más espacio a los contenidos informativos, que con frecuencia anteceden a la exposición de los contertulios, mientras que en radio la manifestación de opiniones consume la mayor parte del tiempo disponible $\mathrm{y}$ es escaso el material noticioso que se ofrece a los oyentes.

\section{Conclusiones}

1. Atendiendo al grado de pluralismo, las tertulias radiofónicas y televisivas españolas pueden clasificarse en tres grupos: aquellas que presentan una composición equilibrada, con diversidad de opiniones (TVE, RNE); las de sesgo moderado con predominio nítido de contertulios de un determinado signo aunque con algunas voces enfrentadas (Telecinco, Cuatro y Canal Sur Radio); y las abiertamente partidistas (el resto).

2. Las tertulias radiofónicas de emisores privados se caracterizan por una acentuada falta de pluralidad interna, con un nivel de polarización próximo a 8 sobre 10. Todo apunta a que la diversidad del sistema es usada como coartada para renunciar a la pluralidad propia; la tertulia se convierte, así, en una fórmula de 
enfatización de la línea editorial de la cadena, actuando a modo de "tam-tam” tribal (TORAL, 1997).

3. Las tertulias de televisión de emisores privados también se definen por este perfil, aunque sólo Antena 3 presenta un nivel de parcialidad tan acusado, por encima del de las restantes cadenas. El sesgo, como fenómeno estructural, es un hecho. Hay que inferir, no obstante, que la mayor o menor polarización guarda relación con el aspecto coyuntural de estar ideológicamente alineado o no con el Ejecutivo, ya que la posición antigubernamental tiende más a la dureza que la progubernamental.

4. El medio público -en especial RTVE, pero también Canal Sur- aparece en el sistema audiovisual nacional como trinchera última de la diversidad en la “tertulización” de la agenda: se trata de una constatación firme, por más que la controversia política depare a Televisión Española problemas de aceptación inequívoca (MEdina y OJER, 2009: web). Pese a que desde hace décadas se percibe que los medios públicos están “enfermos” por la presión comercial (PIEDRAHITA, 1995: 98), este indicador es señal de buena salud. La hipótesis teórica de las tertulias como espacios analíticos de alta cualificación informativa para opinar desde "una honesta subjetividad” (Moreno, 2002: 277), no se ve verificada más allá de los espacios públicos, los únicos en los que es posible constatar el propósito de no sesgar la construcción de la realidad.

5. El carácter de espectáculo se añade al atrincheramiento ideológico de las tertulias de emisores privados, de modo que se fomenta el tratamiento de "blanco o negro” (SÁNCHEz SERRANO, 2006). Los conductores a veces contienen la tendencia a un análisis más profundo o un debate más vivo, apostando por el ritmo rápido y el tratamiento superficial de los temas, que ellos fomentan por sistema, de modo que hay una deriva hacia la cultura del entretenimiento infiltrada en los espacios informativos con la etiqueta de "pseudoperiodismos" (PANIAGUA, 2006: 186), que acentúan su éxito en función de un alejamiento del rigor periodístico.

6. La composición de las tertulias desde la perspectiva de género revela una notable escasez de mujeres tanto en radio como en televisión, excepción hecha de TVE y, en menor medida, de Canal Sur Televisión y Cuatro. El desequilibrio resulta muy acusado en los casos de Telecinco y Radio Nacional de España: no existe, por tanto, una pauta que vincule este aspecto con la titularidad pública o privada de las cadenas, aunque sí parece acentuarse en las tertulias radiofónicas frente a las televisivas, conducidas todas por mujeres.

7. La agenda aparece completamente supeditada a la actualidad con matices derivados de la línea editorial de cada medio, mostrando un predominio absoluto de la política nacional incluso en los emisores de naturaleza autonómica, y atendiéndose sólo a los asuntos internacionales cuando existe una óptica nacional desde la que abordarlos. Esto delata una parcialidad de la agenda que excluye áreas clave de la realidad, fomentando la percepción de que existe un temario primario muy reducido.

8. La actividad ejercida en el marco de las tertulias deja, por lo general, poco espacio a la neutralidad, salvo en los casos de RNE y TVE, aunque también Canal 
Sur Televisión y Cuatro se esfuerzan por ofrecer un repertorio variado de posturas. En el resto predominan los juicios críticos o muy críticos hacia el Gobierno, mientras que en algunas cadenas (SER, Canal Sur Televisión) se evita poner en cuestión las políticas del Ejecutivo.

9. Predomina, en la mayoría de los espacios analizados, un tono no analítico aunque más bien moderado, especialmente en televisión. Las excepciones son escasas (Cope).

10. En cuanto a las modalidades de discurso, las tertulias de televisión presentan, frente a las radiofónicas, un mayor equilibrio entre elementos informativos, interpretativos y de opinión.

\section{Referencias bibliográficas}

ARMAÑANZAS, Emy y DÍAZ NOCI, Javier (1997): Periodismo y argumentación. Géneros de opinión. Bilbao, Servicio Editorial de la Universidad del País Vasco.

BARDIN, Laurence (1996): El análisis de contenido. Madrid, Akal.

CEBRIÁN HERREROS, Mariano (1992): Géneros informativos audiovisuales. Madrid, Ciencia 3.

COLLINS, Richard y MURRONI, Christina (1996): New media, new policies, media and communication strategies for the future. Londres, Polity Press.

GARCÍA DE MADARIAGA, José María (2006): "Del periodismo cívico al participativo: nuevos medios, viejas inquietudes”, en Zer, $\mathrm{n}^{\circ} 21$. Bilbao, Servicio de Publicaciones de la Universidad del País Vasco, pp. 203-217.

GUTIÉRREZ, María y HUERTAS, Amparo (2003): "La programación de las radios generalistas en España”, en Zer, no 15. Bilbao, Servicio de Publicaciones de la Universidad del País Vasco, pp. 117-135.

IGARTUA PEROSANZ, Juan José (2006): Métodos cuantitativos de investigación en comunicación. Barcelona, Bosch.

KRIPPENDORFF, Klaus (2002): Metodología de análisis de contenido: Teoría y práctica. Barcelona, Paidós.

MARTÍNEZ-COSTA PÉREZ, María del Pilar y HERRERA DAMAS, Susana (2007): "Radiografía del prime time informativo en la radio española”, en Comunicación, $\mathrm{n}^{\circ}$ 5. Sevilla, Departamento de Comunicación Audiovisual y Publicidad y Literatura de la Universidad de Sevilla, pp. 405-414.

(2008): "La tertulia radiofónica como un tipo de conversación coloquial”, en Doxa Comunicación, $\mathrm{n}^{\circ}$ 5. Madrid, Servicio de Publicaciones de la Fundación Universitaria San Pablo-CEU, pp. 189-211.

MEDINA, Mercedes y OJER, Teresa (2009): "Valoración del servicio público de televisión. Comparación entre la BBC y TVE”, en Revista Latina de Comunicación Social, $\mathrm{n}^{\circ}$ 64: http://www.revistalatinacs.org/09/art/24_823_42 _ULEPICC_11/Medina_y_Ojer.html [fecha de consulta: 4 de junio de 2010].

MIGUEL DE BUSTOS, Juan Carlos (2004):” Sobre pluralismo y diversidad”, en Zer, $\mathrm{n}^{\circ}$ 16. Bilbao, Servicio de Publicaciones de la Universidad del País Vasco, pp. 9-26. 
MORENO ESPINOSA, Pastora (2002): "La tertulia radiofónica, foro para el siglo XXI", en Estudios sobre el Mensaje Periodístico, $\mathrm{n}^{\circ}$ 8. Madrid, Servicio de Publicaciones de la Universidad Complutense, pp. 275-291.

MURCIANO, Marcial (2006): "Las políticas de comunicación ante los retos del nuevo milenio: pluralismo, diversidad cultural, desarrollo económico y tecnológico y bienestar social”, en Zer, $\mathrm{n}^{0}$ 20. Bilbao, Servicio de Publicaciones de la Universidad del País Vasco, pp. 371-398.

NÚÑEZ LADEVÉZE, Luis (1995): Introducción al periodismo escrito. Barcelona, Ariel.

ONDA CERO RADIO (1996): Guía de estilo. Madrid, Onda Cero Radio.

PANIAGUA SANTAMARÍA, Pedro (2006): "Deporte en televisión: el pseudoperiodismo como espectáculo”, en Estudios sobre el Mensaje Periodístico, $\mathrm{n}^{\circ}$ 12. Madrid, Servicio de Publicaciones de la Universidad Complutense, pp. 185-193.

PIEDRAHITA, Manuel (1995): "El rapto de la televisión pública”, en Estudios sobre el Mensaje Periodístico, $\mathrm{n}^{\circ}$ 2. Madrid, Servicio de Publicaciones de la Universidad Complutense, pp. 85-100.

SÁNCHEZ ARANDA, José Javier (2005): “Análisis de contenido cuantitativo de medios”, en BERGANZA CONDE, María Rosa y RUIZ SAN ROMÁN, José Antonio (coords.): Investigar en Comunicación. Madrid, McGraw Hill, pp. 207228.

SÁNCHEZ SERRANO, Consuelo (1994): Las tertulias de la radio. La plaza pública de los 90. Salamanca, Publicaciones de la Universidad Pontificia de Salamanca.

(2006): "Las tertulias políticas de la radio española: un ejercicio de comunicación política mejorable”, en Comunicación y Pluralismo $\mathrm{n}^{\circ} 0$. Salamanca, Servicio de Publicaciones de la Universidad Pontificia, pp. 141-152.

SANTAMARÍA, Luisa (1992): "Las tertulias radiofónicas y televisivas, manifestaciones atípicas del periodismo de opinión”, en Periodística, $\mathrm{n}^{\circ} 5$. Barcelona, Institut d'Estudis Catalans, pp. 129-134.

- y CASALS CARRO, María Jesús (2000): La opinión periodística. Argumentos y géneros para la persuasión. Madrid, Fragua.

TORAL, Gotzon (1997): "Las tertulias de la radio: El tam-tam de la tribu” en Zer. Bilbao, Servicio de Publicaciones de la Universidad del País Vasco, $n^{\circ}$ 3, pp. 97109. 